\title{
Propafenone Hydrochloride
}

National Cancer Institute

\section{Source}

National Cancer Institute. Propafenone Hydrochloride. NCI Thesaurus. Code C47692.

The hydrochloride salt form of propafenone with class 1C antiarrhythmic effects.

Propafenone hydrochloride stabilizes the neuronal membrane by binding to and inhibiting voltage-gated sodium channels, thereby reducing sodium influx required for the initiation and conduction of impulses in Purkinje and myocardial cells. This agent produces a marked depression of phase 0 and prolonged effective refractory period in the atrioventricular nodal and His-Purkinje tissue, resulting in a profound decrease in excitability, conduction velocity and automaticity, thereby counteracting atrial and ventricular arrythmias. 